\title{
PENGARUH DIMENSI BUDAYA DAN KOMUNIKASI TERHADAP PRESEPSI KONSUMEN SERTA IMPLIKASINYA TERHADAP PURCHASE DECISION PELANGGAN E-COMMERCE DI JAKARTA
}

\author{
Choiril Maksum, Mochammad Jasin dan Nurezas
}

\begin{abstract}
Abstrak
Teknologi informasi yang berkembang sangat pesat dimanfaatkan oleh sektor usaha dan industry untuk meningkatkan produktifitas. Salah satu cara dengan menggunakan platform ecommerce, cara ini dinilai sangat potensial karena Indonesia merupakan salah satu market ecommerce terbesar di Asia Tenggara. Masyarakat atau pengguna internet kini lebih cenderung membeli ataupun review barang atau jasa secara on-line. Artinya preferensi pembelian sebagian masayarakat mulai mengalami perubahan, hal ini membuat pergeseran budaya pembelian dari konvensional menjadi secara on-line. Maka adanya pergeseran budaya dengan ditunjang penggunaan instrumen komunikasi pemasaran oleh sektor usaha, dapat diukur prespsi konsumen atas e-commerce yang kemudian apakah berimplikasi terhadap purchase decision.

Obyek penelitian ini adalah pelanggan e-commerce di Jakarta lalu teknik penentuan sample adalah non probability sampling dengan jumlah sample sebanyak 120 responden. Metode analisis menggunakan Structural Equation Model berbasis variance atau Partial Least Square. Berdasarkan analisis jawaban angket responden didapati seluruh indikator dinyatakan valid dan reliable dan model yang diteliti dikategorikan marginal fit. Hasil penelitian dapat disimpulkan seluruh variabel dimensi budaya berpengaruh terhadap presepsi konsumen sedangkan hanya variabel uncertainty avoidance yang berpengaruh terhadap purchase decision. Untuk dimensi komunikasi hanya variable advertising yang berpengaruh terhadap presepsi konsumen sedangkan seluruh variable dimensi komunikasi tidak berpengaruh terhadap purchase decision.
\end{abstract}

Kata Kunci: E-commerce, Dimensi Budaya, Komunikasi Pemasaran, Consumer Behaviour

\section{PENDAHULUAN}

\subsection{Latar Belakang Masalah}

Sebelum menggunakan teknologi dalam kegiatan usahanya individu ataupun perusahaan mengandalakan dua metode yang popular yakni direct selling dan distribution channel. Dari dua metode tersebut pada era modern saat ini memiliki kekurangan dalam hal penyampaian produk dan jasa. Untuk membantu serta memudahkan penyampaian barang dan jasa maka penggunaan teknologi dan internet merupakan jawaban dan juga salah satu keharusan, dengan cara membuat sebuah portal on-line atau yang dikenal sebagai e-commerce.

Fungsi dari e-commerce itu sendiri dapat dilihat dari tiga aspek yakni perdagangan (commerce), fungsi bisnis dan kerjasama (collaboration). Maka dari tiga aspek tersebut e-commerce dapat di definisikan sebagai media teknologi jejaring komunikasi (telecommunication network) untuk melakukan suatu transaksi bisnis, pertukaran informasi dan menjaga hubungan dengan konsumen baik sebelum, selama, dan setelah proses pembelian (Vera Pujiani dan Eri Besra, 2009 : 2). 
Berdasarkan penelitian yang dilakukan oleh DBS Asia Indonesia merupakan pasar e-commerce terbesar di Asean dengan nilai transaksi USD 1,1 Milyard. Berikut ini infografis dari penelitian tersebut :

\section{Gambar 1}

Referensi Penelitian

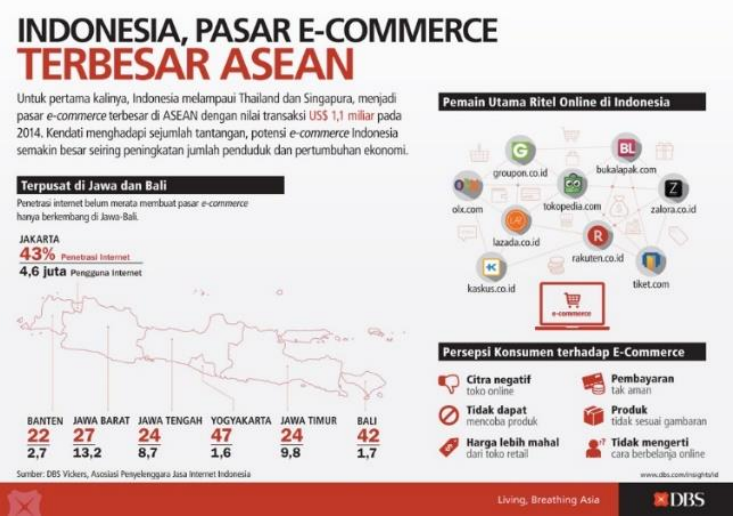

Infografis diatas menunjukan

bahwasanya terdapat potensi ekonomi yang besar. Selain itu juga terdapat potensi resiko seperti yang dipersepsikan oleh konsumen. Potensi resiko tersebut seharusnya membuat perkembangan bisnis e-commerce tidak terlalu berkembang tetapi berlaku sebaliknya dan membuat sebuah paradox. Dimana $e$ commerce begitu sangat popular dan sudah menjadi lifestyle bagi sejumlah pengguna internet.

Hal ini juga ditunjang dengan penetrasi pengguna internet, seperti yang dikutip dari penelitian idEA (Indonesian ECommerce Association) jumlah pengguna internet atau on-line user sebanyak 75 juta. Lalu dari data yang dipublikasi oleh World Economic Outlook Internet Services Providers Asociation pertumbuhan pasar $e$ - commerce di Indonesia selalu meningkat dari tahun ke tahun. Berikut ini infografis dari data penelitian tersebut :

\section{Gambar 2}

\section{Statistik Pertumbuhan Pasar E-Commerce}

\begin{tabular}{|c|c|c|c|}
\hline Tahun & $\begin{array}{c}\text { Pasar } \\
\text { E-Commerce } \\
\text { (Rp Triliun) }\end{array}$ & $\begin{array}{l}\text { Jumlah } \\
\text { Penduduk } \\
\text { (Juta) }\end{array}$ & $\begin{array}{c}\text { Jumlah } \\
\text { Konsumen } \\
\text { (Juta) }\end{array}$ \\
\hline 2012 & 4 & 244 & 13 \\
\hline 2013 & 8 & 247 & 20 \\
\hline 2014 & 12 & 251 & 27 \\
\hline 2015 & 18 & 255 & 37 \\
\hline 2016 & 25 & 258 & 49 \\
\hline
\end{tabular}

Berdasarkan kedua penelitian tersebut patut diduga terdapat perubahan budaya dari sebagian konsumen di Indonesia dengan memanfaatkan media teknologi sebagai sarana jual beli produk. Selain itu dengan adanya perubahan budaya turut merubah presepsi konsumen atas layanan $e$ commerce yang berimplikasi terhadap keputusan pembelian. Kemudian sangatlah menarik untuk melakukan penelitian dengan topik consumer behavior e-commerce di Indonesia dengan cakupan perubahan pola budaya pembelian serta preferensi pembelian secara on-line. Maka judul yang diajukan pada penelitian ini adalah "Pengaruh Dimensi Budaya dan Komunikasi Terhadap Persepsi Konsumen Serta Implikasinya Terhadap Purchase Decision pelanggan $e$ commerce di Indonesia”.

Berdasarkan latar belakang masalah yang telah dipaparkan pada bagian terdahulu, 
maka dapat dirumuskan permasalahan sebagai berikut :

a) Apakah dimensi budaya yang diwakili oleh uncertainty avoidance, group attachment dan time orientation serta dimensi komunikasi yang diwakili oleh advertising, sales promotion dan public relation dari penyedia jasa e-commerce berpengaruh terhadap persepsi konsumen e-commerce di Indonesia ?.

b) Apakah dimensi budaya yang diwakili oleh uncertainty avoidance, group attachment dan time orientation serta dimensi komunikasi yang diwakili oleh advertising, sales promotion dan public relation dari penyedia jasa e-commerce berpengaruh terhadap purchase decision konsumen e-commerce di Indonesia ?.

c) Apakah persepsi konsumen berpengaruh terhadap purchase decision konsumen $e$ commerce di Indonesia?

\subsection{Rumusan Masalah}

Berdasarkan latar belakang masalah yang telah dipaparkan pada bagian terdahulu, maka dapat dirumuskan permasalahan sebagai berikut :

a) Apakah dimensi budaya yang diwakili oleh uncertainty avoidance, group attachment dan time orientation serta dimensi komunikasi yang diwakili oleh advertising, sales promotion dan public relation dari penyedia jasa e-commerce berpengaruh terhadap persepsi konsumen e-commerce di Indonesia?. b) Apakah dimensi budaya yang diwakili oleh uncertainty avoidance, group attachment dan time orientation serta dimensi komunikasi yang diwakili oleh advertising, sales promotion dan public relation dari penyedia jasa e-commerce berpengaruh terhadap purchase decision konsumen e-commerce di Indonesia ?.

c) Apakah persepsi konsumen berpengaruh terhadap purchase decision konsumen $e$ commerce di Indonesia?.

\section{TINJAUAN PUSTAKA}

\subsection{E-Commerce}

Secara ilmiah e-commerce didefinisikan sebagai sebuah system pendistibusian barang/jasa menggunakan media elektoronik yang berbasiskan platform teknologi. Catherine L. Mann (2000), mengemukakan bahwasanya e-commerce bukan merupakan sebuah jasa atau sebuah barang, tetapi merupakan perpaduan antara jasa dan barang. Dengan aplikasi ecommerce, seyogyanya hubungan antar perusahaan dengan entitas eksternal lainnya (pemasok, distributor, rekanan, konsumen) dapat dilakukan secara lebih cepat, lebih intensif, dan lebih murah dibandingkan dengan mengaplikasikan prinsip manajemen secara konvensional (door to door ataupun one-to-one relationship).

Menurut Simarmata (2005 : 329) secara umum e-commerce dibagi menjadi tiga jenis model bisnis dengan karakteristik berbeda-beda yakni : 
a) Business to Business (B2B)

Model e-commerce dari B2B adalah trading partners-nya telah diketahui dan umumnya memiliki hubungan yang cukup lama serta informasi hanya dipertukarkan dengan partner bisnisnya. Kemudian adanya data exchange secara berlangsung berulang-ulang dan berkala.

b) Business to Customer (B2B)

Model e-commerce $\mathrm{B} 2 \mathrm{C}$ terbuka untuk umum, dimana informasi atas produk, company profile serta term of payment disebarkan ke umum. Kedua, servis yang diberikan bersifat umum dimana mekanismenya dapat digunakan oleh khalayak ramai. Ketiga, pelayanan yang diberikan berdasarkan permohonan (on demand) maka produsen mempersiapkan responnya sesuai dengan permohonan tersebut. Keempat, pendekatan client atau server sering digunakan dimana diambil asumsi client (consumer) menggunakan sistem yang minimal (berbasis Web) dan processing (business procedure) diletakkan di sisi server (Deris, 2002).

c) Customer to Customer (C2C) Consumer-to-consumer e-commerce atau C2C didefinisikan sebagai perdagangan antara individu (sektor swasta ataupun individu) dengan konsumen. Dimana mekanisme bisnis consumer to consumer (C2C) difasilitasi oleh adanya marketplace yang menyediakan fasilitas berupa platform e-commerce dan aktivitas mekanisme pembayaran transaksi. Jadi skema bisnis pada model ini melibatkan tiga subyek yakni seller, marketplace dan consumer.

Dalam mengimplementasikan $e$ commerce tersedia suatu integrasi rantai nilai dari infrastrukturnya, yang terdiri dari tiga lapis. Pertama, insfrastruktur sistem distribusi (flow of good); kedua, insfrastruktur pembayaran (flow of money); dan ketiga, infrastruktur sistem informasi (flow of information). Agar dapat terintegrasinya sistem rantai suplai dari supplier, ke pabrik, ke gudang, distribusi, jasa transportasi, hingga ke pelanggan maka diperlukan integrasi enterprise system untuk menciptakan supply chain visibility. Ada tiga faktor yang patut dicermati oleh kita jika ingin membangun e-commerce yaitu: variability, visibility, dan velocity (Majalah Teknologi ; 2001).

\subsection{Budaya}

Faktor budaya memberikan pengaruh yang paling luas terhadap pola perilaku konsumen seperti yang dikemukakan oleh Geert Jan Hofstede (Kussudyarsana, 2008 : 173) budaya merupakan keseluruhan interaksi dari karakteristik umum yang mempengaruhi respon kelompok terhadap lingkungannya. Sedangkan Purimahua (2005 : 545) menyatakan faktor budaya adalah kebiasan suatu masyarakat dalam menanggapi sesuatu yang dianggap memiliki nilai dan kebiasaan, yang bisa dimulai dari mereka menerima informasi, posisi sosial 
mereka dalam masyarakat, dan pengetahuan mereka tentang apa yang mereka rasakan.

Geert Jan Hofstede melakukan penelitian untuk memahami variasi culture secara komperhensife di 50 lebih negara. Penelitian yang di lakukan dihasilkan lima dimensi budaya atas pengukuran variasi culture tersebut. Berikut ini dijelaskan lima dimensi budaya seperti yang dikemukakan oleh Geert Jan Hofstede (Devia Arda, 2012 : 5) :

a) Power Distance

Merupakan sejauh mana para anggota yang kurang berkuasa dalam organisasi dan institusi meerima bahwa kekuasaan didistribusikan secara tidak merata. Hal ini mencerminkan dari anggota yang kurang berkuasa dalam masyarakat maupun mereka yang mempunyai kekuasaan lebih.

b) Individualism

Merupakan kriteria yang
menggambarkan kurangnya ikatan antar anggota suatu masyarakat dimana seseorang hanya memikirkan dirinya atau keluarga/kerabat dekatnya semata. Sedangkan kolektivisme lebih menekankan pada kekohesivan kelompok, menunjukkan keterikatan kuat antara individu dengan masyarakatnya, dimana masyarakatnya memberikan perlindungan bagi individu tersebut dan adanya loyalitas diantara mereka.

c) Masculinity
Merupakan situasi dimana nilai-nilai dominan dalam masyarakat adalah sukses, uang dan harta benda. Berdasarkan pengukuran Hofstede, semakin kecil tingkat maskulinitas masyarakat berarti masyarakat tersebut bersifat feminine. Sedangkan feminitas adalah situasi dimana nilai-nilai yang dominan dalam masyarakat adalah kepedulian kepada orang lain dan keselarasan serta ketentraman hidup (quality of life).

d) Uncertainty Avoidance

Merupakan sejauh mana orang merasa terancam dengan situasi yang tidak pasti, tidak diketahui, ambigu dan tidak terstruktur. Perasaan ini menunjukkan adanya kekhawatiran dan keinginan masyarakat untuk dapat memprediksi situasi yang akan datang. Penghindaran ketidakpastian mengukur tingkat kegelisahan anggota masyarakat atau institusi mengenai ketidakpastian atau ketidaktahuan mengenai masa depan.

e) Long Term Orientation

Memberikan penjelasan mengenai kecenderungan masyarakat untuk lebih memperhatikan pada jangka panjang atau jangka pendek dalam kehidupan mereka. Orientasi jangka panjang mengembangkan kebaikan-kebaikan dengan orientasi reward di masa mendatang dalam bentuk ketekunan dan penghematan. Sebaliknya, orientasi jangka pendek, mewakili 
mengembangkan kebaikan-kebaikan

berhubungan dengan masa lalu, menghormati tradisi, pemeliharaan citra diri dan memenuhi kewajiban-kewajiban sosial.

Penelitan yang dilakukan oleh Geert Jan Hofstede lalu dikembangkan oleh Nguyen Phuong Mai (2015). Dimensi budaya dari Geert Jan Hofstede dikelompokan menjadi tiga cakupan yakni individual value, collective value dan universal value. Penelitian yang dikembangkan didasari atas penelitian Geert Jan Hofstede yang hanya fokus pada collective value. Berikut adalah dimensi budaya yang dikembangkan oleh Nguyen Phuong Mai:

a) Power Distance

Dimensi ini didefinisikan sebagai sejauh mana anggota masyartakat yang kurang kuat mampu menerima kekuatan yang tidak terdistribusi tidak merata. Pada cakupan collective value semua anggota masyarakat memiliki kesamaan fundamental dimana setiap orang atau anggota masyarakat harus memiliki kekuatan yang lebih dari yang lain. Kemudian secara universal setiap individu atau masyarakat pasti memiliki derajat yang tidak sama. Power Distance dapat diukur untuk setiap individu bagaimana kecendrungan menerima ketidaksetaraan, secara individual jawaban dari seseorang pasti seragam dan hal ini membuat kompleksitas individual. b) Group Attachment

Pada dimensi yang kedua ini merupakan gagasan yang dibuat atas dasar pada penelitain Geert Jan Hofstede yang tidak memberi nama secara universal. Kemudian group attachment didefinisikan secara universal adalah hubungan eksklusif antara individu dalam suatu kelompok masyarakat. Lalu secara collective value hubungan tersebut dinilai menjadi dua apakah suatu individu dalam berhubungan dengan anggota masyarakat lebih cendrung individualistis atau melibatkan anggota individu lain, ini yang disebut kolektifitas. Nantinya akan dinilai secara individual apakah lebih cenderung individualistis atau kolektif.

c) Gender Association

Pada dimenisi ini merupakan pengembangan dimensi dari Geert Jan Hofstede yakni masculinity-feminimity. Hal ini berawal dari asumsi psikologis dimana kita masih mendikotomikan presepsi nilai individual atas pria dan wanita meski secara realitas semakin convergent. Secara collective value kita memisahkan gender role yang mengindikasikan sifat antara pria dan wanita (masculinity-feminimity). Lalu berbeda dengan collective value secara universal gender role dikombinasikan bahkan terdapat hal yang disetarakan.

d) Uncertainty Avoidance

Pada level individual dimensi ini erat kaitanya dengan truth, yakni bagaimana 
individu menyikapi suatu ketidak pastian.

Kemudian secara kolektif suatu kelompok masyarakat memiliki pandangan yang berbeda untuk menghindari kepastian, beberapa society culture mengelompokan pada dua orientasi yakni ketidakpastian kuat atau lemah. Lalu berdasarkan orientasi ini anggota masyarakat akan melakukan social activities untuk menyikapinya apakah secara individual atau kolektif.

\section{e) Time Orientation}

Dimensi ini menitikberatkan bagaimana idividu merencanakan suatu hal yang akan datang. Secara collective value spektrum waktu dapat berbeda-beda pada setiap culture society yang berorientasi apakah short term orientation yang fokus pada masa lalu dan kini atau long term orientation yang fokus pada masa yang akan datang.

\subsection{Komunikasi Pemasaran}

Pada dasarnya komunikasi pemasaran merupakan aktivitas yang mencakup kegiatan menyebarkan informasi, mempengaruhi, membujuk dan atau mengingatkan target pasar agar bersedia untuk meminta, membeli, dan loyal pada produk barang ataupun jasa yang ditawarkan perusahaan bersangkutan (Fandy Tjiptono, 2008:219). Sedangkan menurut Philip Kotler (Benyamin Molan, 2004:604) integrated marketing communication atau komunikasi pemasaran adalah konsep dasar bagi perusahaan untuk memadukan dan mengkoordinasikan semua saluran komunikasinya untuk menyampaikan pesan yang jelas, konsisten, dan berpengaruh kuat tentang organisasinya dan produk-produknya.

Seperti yang dikemukakan oleh Soemanagara (2012 : 1) Konsep integrated marketing communication menganjurkan perusahaan harus mengkombinasikan alatalat promosi secara seksama ke dalam sebuah bauran komunikasi pemasaran yang terkoordinasi dengan baik. Integrated marketing commnunication merupakan penggabungan dari lima model komunikasi yang membentuk sebuah dimensi komunikasi yakni advertising, sales promotion, public relations, personal selling dan direct selling.

Setelah komunikasi disampaikan kepada konsumen maka selanjutnya perusahaan dapat mengukur efektifitas komunikasi tersebut. EPIC Model dapat digunakan untuk melakukan pengukuran efektivitas dan dampak komunikasi dalam pemasaran. Model ini ditemukan dan dikembangkann oleh lembaga penelitian AC. Nielsen. EPIC model merupakan salah satu dimensi dari komunikasi yang terdiri dari empat atribut (Susilawati, $2016: 66$ ).

a) Empation

menginformasikan, apakah konsumen menyukai komunikasi pemasaran dari marketer, dan bagaiman konsumen melihat hubungan komunikasi pemasaran tersebut dengan pribadi mereka. Empati merupakan keadaan mental yang 
membuat seseorang mengidentifikasikan

dirinya atau merasa dirinya pada keadaan perasaan atau keadaan yang sama dengan orang atau kelompok lain. Dimensi empati dapat menggambarkan keadaan positif maupun negatif dari suatu kegiatan komunikasi promosi.

b) Persuation

Menginformasikan apa yang dapat diberikan suatu komunikasi pemasaran untuk peningkatan atau penguatan karakter suatu merk, sehingga marketer dapat memperoleh pemahaman tentang dampak komunikasi pemasaran terhadap keinginan konsumen untuk membeli suatu produk yang ditawarkan. Persuasi adalah perubahan kepercayaan, sikap dan keinginan berprilaku yang disebabkan oleh komunikasi promosi dan sesuatu yang dapat menarik seseorang untuk melakukan suatu hal tertentu.

c) Impact

Menunjukkan apakah suatu produk bisa terlihat lebih menonjol daripada produk lain, dan apakah suatu komunikasi pemasaran dapat mengikutsertakan konsumen dalam pesan yang disampaikan. Tujuan dari dimensi dampak adalah peningkatan product knowledge (pengetahuan produk).

d) Communication

Memberikan informasi tentang kemampuan konsumen dalam mengingat pesan utama yang disampaikan, pemahaman konsumen, kekuatan kesan yang ditinggalkan dan kejelasan komunikasi pemasaran.

\subsection{Presepsi Konsumen}

Pada dasarnya presepi konsumen merupakan salah satu faktor yang mempengaruhi pilihan konsumen untuk membeli ataupun memakai produk atau jasa. Seperti yang dikemukakan oleh Suryani (2012 : 97) presepsi konsumen merupakan proses dimana individu memilih, mengorganisasikan dan mengintepretasikan stimuli menjadi suatu yang bermakna. Proses presepsi akan diawali oleh suatu stimuli yang mengenai indera kita dan stimuli yang menimbulkan persepsi bisa bermacammacam bentuknya, asal merupakan sesuatu yang langsung mengenai panca indera kita, seperti segala sesuatu yang bisa dicium, segala sesuatu yang bisa dilihat, segala sesuatu yang bisa didengar, segala sesuatu yang bisa diraba.

Sesuatu yang di presepsikan oleh konsumen pada dasarnya diawali oleh suatu proses seleksi perseptual dimana konsumen menangkap dan memilih stimulus dari berbagai informasi yang ada dalam memorinya. Pada proses ini terdapat dua subproses yakni perhatian dan persepsi selektif. Perhatian dari konsumen dapat terjadi secara sengaja (voluntary atention) dan tidak sengaja (involuntary atention). Voluntary attention terjadi ketaika konsumen memiliki keterlibatan tinggi terhadap produk dan konsumen secara aktif mencari informasi mengenai produk dari berbagai sumber. 
Involuntary attention terjadi ketika konsumen dipaparkan stimuli berupa hal-hal yang dapat menarik konsumen atau tidak terduga dan tidak berhubungan dengan tujuan atau kepentingan konsumen. Secara otomatis jika konsumen dipaparkan stimuli seperti itu akan langsung memberikan respon (Aristo Surya et al, 2009 : 17).

Setelah proses seleksi dilakukan selanjutnya adalah proses pengorganisasian dimana pada proses ini konsumen mengelompokan segala informasi yang didapat. Artinya, konsumen akan mengintegrasikan berbagai stimulus untuk memberikan deskripsi lengkap tentang suatu obyek sehingga memudahkan mereka dalam memproses informasi dan memberikan pengertian yang terintegrasi terhadap stimulus. Proses terakhir dari presepsi yaitu memberikan interpretasi atas stimuli yang diterima oleh konsumen. Dalam proses ini, konsumen membuka kembali berbagai informasi yang terekam dalam memori jangka panjang yang berhubungan dengan stimulus yang diterima (Aristo Surya et al, 2009 : 17) .

\subsection{Keputusan Pembelian}

Keputusan pembelian merupakan suatu tahapan dalam proses pembelian suatu produk ataupun jasa. Menurut Basu Swastha dan Irawan (2008:118) keputusan pembelian adalah pemahaman konsumen tentang keinginan dan kebutuhan akan suatu produk dengan menilai dari sumber-sumber yang ada dengan menetapkan tujuan pembelian serta mengidentifikasi alternatif sehingga pengambil keputusan untuk amembeli yang disertai dengan perilaku setelah melakukan pembelian.

Seperti yang dikemukakan Basu Swastha (Rhendria Dinawan, 2010 : 22) untuk memahami konsep perilaku konsumen dalam memenuhi kebutuhanya dapat dikemukakan dua model proses pembelian yang dilakukan oleh konsumen, yaitu :

a) Model phenomenologis, model perilaku konsumen ini berusaha mereprodusir perasaan-perasaan mental dan emosional yang dialami konsumen dalam memecahkan masalah pembelian yang sesungguhnya.

b) Model logis, model perilaku konsumen yang berusaha menggambarkan struktur dan tahap-tahap keputusan yang diambil konsumen mengenai (a) jenis, bentuk, modal, dan jumlah yang akan dibeli, (b) tempat dan saat pembelian, (c) harga dan cara pembayaran.

\section{Kerangka Pemikiran}

Penelitian e-commerce yang dijadikan obyek penelitian ini melibatkan tiga subyek yakni seller, penyedia platform e-commerce serta customer ataupun calon customer. Dari sisi konsep bisnis seller memanfaatkan platform e-commerce yang disediakan oleh penyedia jasa layanan. Dengan memanfaatkan feature platform ecommerce seller maka dapat berkomunikasi serta membangun kepercayaan agar customer mempunyai niatan untuk membuat keputusan 
membeli barang yang dijual (purchase decision).

Sedangkan dari sisi customer pasti akan mempelajari dari apa yang di komunikasikan oleh seler dan penyedia platform $e$ commerce. Kemudian customer mempersepsikan apa yang disampaikan, terutama persespsi akan resiko (uncertainty avoidance). Persepsi tersebut yang paling dominan yang timbul dalam model bisnis $e$ commerce ini. Dikarenankan banyak faktor yang mempengaruhi karena kodisi seller dan customer tidak bertemu secara langsung. Ketika semua faktor yang ada di filter oleh customer maka akan muncul keputusan apakah terdapat minat untuk membeli atau tidak. Untuk memperjelas hubungan yang dibangun berdasarkan kerangka pemikiran dan kajian teoritis berikut ini gambar dari skema penelitian:

\section{Gambar 3}

Skema Penelitian

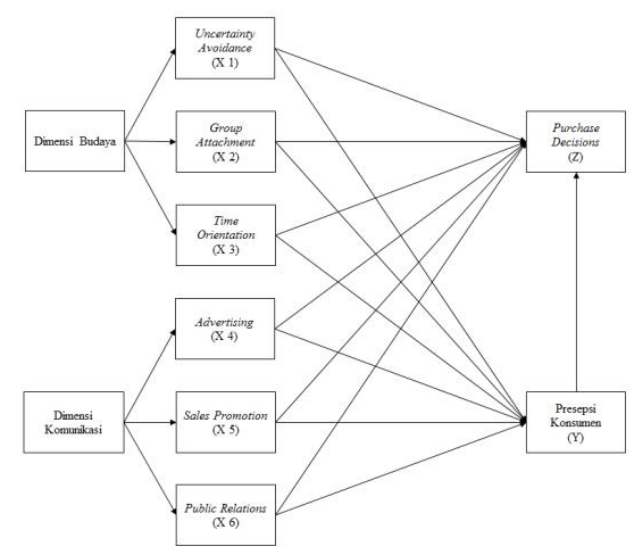

Keterangan Gambar :

Pada gambar diatas dimensi budaya diwakili oleh uncertainty avoidance, group attachment serta time orientation dan dimensi komunikasi pemasaran diwakili oleh advertising, sales promotion serta public relations. Kedua dimensi variabel ini akan membentuk sebuah konstruksi hubungan dengan presepsi konsumen secara langsung dan terhadap purchase decision yang secara langsung atau dimediasi oleh preepsi konsumen. Sedangkan presepsi konsumen yang diukur berdasarkan konstruk akan dicari hubungan secara langsung terhadap purchase decision.

\section{METODOLOGI PENELITIAN}

\subsection{Variabel Penelitian}

Pada penelitian ini menggunakan tiga jenis variabel seperti yang sudah dijelaskan sebelumnya pada bagian desain penelitian. Berikut ini adalah penjelasan dari ketiga variabel tersebut seperti yang dikemukakan oleh Sugiono (2006 : 33):

a) Variabel independen ataupun variabel eksogen merupakan variabel yang mempengaruhi atau yang menjadi sebab perubahanya atau timbulnya variabel dependen. Variabel eksogen dalam penelitian ini adalah atribut dimensi budaya yang terdiri dari uncertainty avoidance, group attachment, dan time orientation serta atribut dimensi komunikasi yang terdiri dari advertising, sales promotion dan public relations.

b) Variabel moderator atau disebut juga dengan variabel bebas kedua yakni variabel yang dipilih, diukur, diamati dan dimanipulasi oleh peneliti karena diduga 
ikut mempengaruhi hubungan antara variabel eksogen dan variabel endogen. Pada penelitian ini variabel moderator diwakili oleh presepsi konsumen.

c) Variabel dependen ataupun variabel endogen merupakan variabel yang dipengaruhi atau yang menjadi akibat, karena adanya variabel bebas. Variabel endogen dalam penelitian ini adalah purchase decision.

\subsection{Definisi Operasional Variabel}

Definisi operasional adalah suatu definisi yang memberikan arti atau menspesifikasikan kegiatan ataupun membenarkan sesuatu operasional yang diperlukan untuk mengukur atribut dimensi yang dijadikan variabel. Dalam penelitian ini definisi operasional dari variabel yang diteliti adalah sebagai berikut: 
Tabel 1

\section{Definisi Operasional}

\begin{tabular}{|c|c|c|c|}
\hline Dimensi & Variabel & Definisi Variabel & Indikator \\
\hline \multirow{9}{*}{ Budaya } & \multirow{3}{*}{ Uncertainty Avoidance } & \multirow{3}{*}{$\begin{array}{l}\text { Pada atribut dari dimensi budaya ini didefinisikan sebagai suatu perasaan atau asumsi } \\
\text { dari konsumen akan kekhawatiran atas suatu hal yang kurang pasti dalam melakukan } \\
\text { pembelian e-commerce }\end{array}$} & a. Kekahawatiran akan bentuk fiskik dari suatu produk \\
\hline & & & 6. Ketharvatiran akan kinerja dari barang dann yang ditoeli \\
\hline & & & c. Kelkhawatiran adanya penipuan pasca pembelian. \\
\hline & \multirow{3}{*}{ Group Attachment } & \multirow{3}{*}{$\begin{array}{l}\text { Pada atribut dari dimensi budaya ini didefinisikan sebagai kecendrungan keterlibatan } \\
\text { fungsi sosial secara individualisme atau kolektivisme untuk melakukan pembelian e- } \\
\text { commerce }\end{array}$} & a. Berkomumikasi dengan penjual atas produlk yang ditawarkan. \\
\hline & & & 6. Mencari referensi produk atau dari pembetl lain \\
\hline & & & c. Membuat testimoni pasca pembetian \\
\hline & \multirow{3}{*}{ Time Orientation } & \multirow{3}{*}{$\begin{array}{l}\text { Pada atribut dari dimensi budaya ini didefinisikan sebagai ketepatan dan kecepatan } \\
\text { penyampaian barang atau jasa dalam pembelian melalui e-commerce }\end{array}$} & a. Kemudahan dalam mencari barang yang sesulaik kebutuhan dengan cepat \\
\hline & & & 6. Kemudahan mengkomparasi barang sejenis yang akan dibeli dengan cepat \\
\hline & & & c. Efisiensi dalam mekanisme pengiriman barang \\
\hline \multirow{9}{*}{ Komunikasi } & \multirow{3}{*}{ Advertising } & \multirow{3}{*}{$\begin{array}{l}\text { Pada atribut dari dimensi komunikasi pemasaran ini diartikan sebagai cara dari seller } \\
\text { ataupun penyedi jasa platform e-commerce untuk menvajikan promosi non-personal } \\
\text { tentang gagasan ataupun produk menggunakan media cetak ataupun elektronik }\end{array}$} & a. Konsumen mentyuka cara ataupun bentuk advertising dari marketer \\
\hline & & & b. Bertambahnya product knowledge dari konsumen \\
\hline & & & c. Kosumen mengingat pesan utama yanng disampaikan dari advertising \\
\hline & \multirow{3}{*}{ Sales Promotion } & \multirow{3}{*}{$\begin{array}{l}\text { Pada atribut dari dimensi komunikasi pemasaran ini diartikan sebagai short-term } \\
\text { incentive dari seller atau penyedia jasa e-commerce untuk mendorong penjualan } \\
\text { produk ataupun jasa }\end{array}$} & a. Konsumen tettarlk dengan discount yang diberklkan oleh seller/penvedia e-commerce \\
\hline & & & b. Konsumen tertarlk dengan program bexing allowance dari seller penyedia e-commerce \\
\hline & & & c. Konsumen tertarik dengan penawaran promotional product dari seller penvedia e-commerce \\
\hline & \multirow{3}{*}{ Public Relation } & \multirow{3}{*}{$\begin{array}{l}\text { Pada atribut dari dimensi komunikasi pemasaran ini diartikan sebagai cara seller atau } \\
\text { penyedia jasa e-commerce untuk membangun citra yang baik dimata publik }\end{array}$} & a. Halaman website frequently ask and question sangat informatif bagi konsumen \\
\hline & & & b. Newsletter membanth konsumen mendapatkan informasi akan promosi a atau product knowledge \\
\hline & & & c. Autoresponder e-mail message membantu konsumen untuk menanyakan produlk ataupun keluhan \\
\hline & \multirow{3}{*}{ Presepsi Konsumen } & \multirow{3}{*}{$\begin{array}{l}\text { Variabel ini diartikan sebagai suatu proses yang dialami oleh konsumen untuk } \\
\text { memilih, mengorganisasikn serta menginterpretasikan dari informasi yang didapat } \\
\text { tentang layanan e-commerce }\end{array}$} & a. Konsumen merass nyaman berbelanja menggunakan layanan e-commerce \\
\hline & & & b. Sistem pembayaran e-comnerce sangat memudahkan konsumen \\
\hline & & & c. Proses pelayaman yang diriasa cepat dan tepat oleh konssumen \\
\hline & \multirow{3}{*}{ Purchase Decision } & \multirow{3}{*}{$\begin{array}{l}\text { Variabel ini diartikan sebagai tindakan yang diambil leeh konsumen untuk melakukan } \\
\text { pembelian melalui e-commerce berdasarkan proses pembelajaran serta evaluasi atas } \\
\text { layanan ataupun barang yang akan dibeli }\end{array}$} & a. Konsumen bersedia untuk melakkikan pembetian melalui e-commerce \\
\hline & & & b. Konsumen bersedia membeli kembali barang yang permah dibeli ataupun barang lain melahu e-commerce \\
\hline & & & $\begin{array}{l}\text { c. Konsumen bersedia unthik membuat testimonial atau mereferenskikan barang y yang dibeli ataupun layan dari e- } \\
\text { commerce }\end{array}$ \\
\hline
\end{tabular}




\section{Populasi dan Sample}

Pada penelitian yang dilakukan bahawasannya anggota populasi tidak diketahui besarannya. Teknik penentuan sampel yang digunakan adalah non probability sampling teknik tersebut dapat diartikan sebagai pengambilan sampel yang tidak memberi peluang atau kesempatan yang sama bagi setiap unsur atau anggota populasi untuk dipilih menjadi sampel. Dari teknik sampling tersebut sampling aksidensial adalah teknik penentuan sampel yang digunakan dalam penelitian ini. Penentuan jumlah sample mengikuti aturan seperti yang dikemukakan oleh Hair et al (2009 : 166) dimana lima observasi dikalikan dengan jumlah indikator. Pada penelitian ini jumlah indikator adalah 24 maka jumlah sampel yang diobservasi berjumlah 120 .

\section{Pengujian Hipotesis}

Atas dasar rumusan masalah yang telah dipaparkan sebelumnya, maka hipotesis kerja (Ha) yang diajukan dalam penelitian yang dilakukan adalah sebagai berikut :

H1 : Diduga uncertainty avoidance mempunyai pengaruh positif terhadap presepsi konsumen e-commerce.

H2 : Diduga group attachment mempunyai pengaruh positif terhadap presepsi konsumen atas layanan e-commerce.

$\mathrm{H} 3$ : Diduga time orientation mempunyai pengaruh positif terhadap presepsi konsumen atas layanan e-commerce.
H4 : Diduga advertising mempunyai pengaruh positif terhadap presepsi konsumen atas layanan e-commerce.

H5 : Diduga sales promotion mempunyai pengaruh positif terhadap presepsi konsumen atas layanan e-commerce.

H6 : Diduga public relations mempunyai pengaruh positif terhadap presepsi konsumen atas layanan e-commerce.

H7 : Diduga presepsi konsumen mempunyai pengaruh positif terhadap purchase decision dengan layanan e-commerce.

H8 : Diduga uncertainty avoidance mempunyai pengaruh positif terhadap purchase decision dengan layanan $e$ commerce.

H9 : Diduga group attachment mempunyai pengaruh positif terhadap purchase decision dengan layanan e-commerce.

H10 :Diduga time orientation mempunyai pengaruh positif terhadap purchase decision dengan layanan e-commerce.

$\mathrm{H} 11$ : Diduga advertising mempunyai pengaruh positif terhadap purchase decision dengan layanan e-commerce.

H12 :Diduga sales promotion mempunyai pengaruh positif terhadap purchase decision dengan layanan e-commerce.

H13 :Diduga public relations mempunyai pengaruh positif terhadap purchase decision dengan layanan e-commerce.

\section{PENGUJIAN HIPOTESIS}

Untuk melakukan pengujian atau analisis model dari hubungan yang 
dikembangkan pada penelitian ini digunakan teknik analisis Partial Least Square. Teknik analisis tersebut merupakan permodelan Structural Equation Modeling (SEM) berebasis variance. Permodelan Structural Equation Modeling berbasis kovarian (Partial Least Square) meniadakan asumsi data harus berdistribusi normal dan tidak mempermasalahkan adanya multikolinieritas antar variable eksogen. Selain itu Partial Least Square dapat diterapkan pada semua skala data dan ukuran sampel yang digunakan tidak harus dengan skala besar. Selain digunakan untuk mengkonfirmasi teori PLS dapat digunakan pula untuk memprediski ada atau tidak hubungan antar variable laten (Theresia Mutiara Galistya, $2017: 19)$.

Analisa pada Partial Least Square dievaluasi berdasarkan pada pengukuran prediksi yang mempunyai sifat non parametrik (Theresia Mutiara Galistya, 2017

: 34). Evaluasi Partial Least Square dilakukan dengan tiga tahapan, yakni:

a) Evaluasi Outer Model

Pada tahapan pertama dalam evaluasi adalah melakukan pengujian terhadap model dapat menggunakan instrument model indikator reflektif dan model indikator formatif. Evaluasi model dengan idikator reflektif dilakukan dengan melakukan uji validitas dan reliabilitas. Sedangkan evaluasi model dengan idikator formatif dilakukan dengan melakukan uji multikolinearitas untuk mengetahui ada atau tidaknya multikolinearitas antar variable laten.

b) Evaluasi Inner Model

Selanjutnya setelah evaluasi outer model masuk dalam kriteria selanjutnya dilakukan evaluasi inner model dengan tujuan untuk memprediski hubungan kausalitas antar variabel laten. Untuk mengevaluasi model dengan melihat nilai koefisien determinasi $\left(R^{2}\right)$ dan goodness of fit index $(\mathrm{GoF})$.

- Interpretasi koefisien determinasi $\left(R^{2}\right)$ dengan melihat seberapa besar variability variable eksogen mampu menjelaskan variable endogen. Selanjutnya nilai diklasifikasikan menjadi tiga kategori yakni lebih besar sama dengan 0.67 dinyatakan substansial, lebih besar sama dengan 0.33 sampai dengan 0.67 dinyatakan moderat dan kurang dari 0.33 dinyatakan lemah (Yamin dan Kurniawan 2011:21).

- Goodnes Of Fit Index digunakan untuk melakukan evaluasi model secara keseluruhan, nilai goodness of fit dijadikan ukuran tunggal sebagai validasi performa gabungan antara model pengukuran dan structural (Tenenhaus et al, 2005). Selanjutnya nilai goodness of fit diklasifikasi menjadi tiga indeks. GFI $\geq 0.9$ dinyatakan good fit, $0,80<$ GFI < 0,90 dinyatakan marginal fit, $0,80<$ 
GFI $<0,50$ dinyatakan close fit (Hair et al, 2009).

c) Pengujian Hipotesa

Setelah kriteria pengujian dinyatakan sesuai dengan ketentuan selanjutnya dapat dilakukan pengujian hipotesis. Pada analisa berbasis Partial Least Square pengujian hipotesis menggunakan metode bootstrapping. Metode ini merupakan teknik nonparametrik untuk menarik kesimpulan inferensial dan sebagai alat bantu untuk mengangani kesalahan pada data berdistribusi normal. Teknik bootstrapping dilakukan dengan membuat data bayangan atau pseudo data menggunakan informasi dari data asli sehingga data resampling mirip dengan data asli.

Metode bootstrapping yang dilakukan memanfaatkan simulasi Monte Carlo dalam melakukan resampling. Tujuan dalam menggunakan teknik simulasi Monte Carlo untuk mempengaruhi sensitivitas dan reliabilitas dari skema yang dimodelkan. Simulasi ini juga merupakan sebagi teknik sampling dikarenakan sampel diulang secara acak sesuai dengan taksiran populasi. Pada penelitian ini pengujian hipotesis dengan melihat nilai t-statistik dan nilai probabilitas. Hipotesis yang dikembangkan diukur dengan membandingkan nilai $t$ hitung dengan $t$ tabel pada tingkat signifikansi $10 \%$.

\section{Analisis dan Pembahasan}

\subsection{Analisis Outer Model}

a) Uji Validitas

Pengujian ini dimaksudkan untuk mengukur kecermatan suatu instrument penelitian dari 24 indikator yang dijadikan pertanyaan kuesioner. Pengujian dilakukan dengan melihat nilai loading factor dimana indikator dinyatakan valid jika bernilai diatas cut off value $70 \%$ atau 0,7. Untuk memudahkan pengujian digunakan software SmartPLS 3.2, berikut ini merupakan hasil pengujian validitas dari atribut yang menjadi pertanyaan dalam kuesioner:

Tabel 2

Nilai Outer Loadings

\begin{tabular}{|c|c|c|c|c|c|c|c|c|}
\hline & AD & GA & PD & PK & PR & SP & TO & UA \\
\hline AD1 & 0.796 & & & & & & & \\
\hline AD2 & 0.826 & & & & & & & \\
\hline AD3 & 0.789 & & & & & & & \\
\hline GA1 & & 0.846 & & & & & & \\
\hline GA2 & & 0.786 & & & & & & \\
\hline GA3 & & 0.782 & & & & & & \\
\hline PD1 & & & 0.720 & & & & & \\
\hline PD2 & & & 0.893 & & & & & \\
\hline PD3 & & & 0.892 & & & & & \\
\hline PK1 & & & & 0.856 & & & & \\
\hline PK2 & & & & 0.815 & & & & \\
\hline PK3 & & & & 0.794 & & & & \\
\hline PR1 & & & & & 0.991 & & & \\
\hline PR2 & & & & & 0.981 & & & \\
\hline PR3 & & & & & 0.991 & & & \\
\hline SP1 & & & & & & 0.780 & & \\
\hline SP2 & & & & & & 0.919 & & \\
\hline SP3 & & & & & & 0.930 & & \\
\hline T01 & & & & & & & 0.928 & \\
\hline TO2 & & & & & & & 0.708 & \\
\hline TO3 & & & & & & & 0.933 & \\
\hline UA1 & & & & & & & & 0.930 \\
\hline UA2 & & & & & & & & 0.921 \\
\hline UA3 & & & & & & & & 0.789 \\
\hline
\end{tabular}

Merujuk teoritis pengujian validitas yang telah dibahas pada bab sebelumnya dengan menggunakan menggunakan metode reflektif dimana pengujian menggunakan bantuan software 
SmartPLs Ver. 3.2 dengan menghitung nilai korelasi antara skor item dengan skor total. Tabel diatas menunjukan nilai loading factor seluruh indikator lebih besar dari nilai cut off value yang dijadikan acuan sebesar 0,7. Berarti indikator yang diukur dalam penelitian ini valid atau memenuhi convergent validity.

b) Uji Reliabilitas

Setelah indikator dinyatakan valid maka selanjutnya dilakukan pengujian prasyarat kedua untuk melihat nilai konsistensi indikator pada setiap variable. Pengujian menggunakan bantuan software SmartPLS Ver. 3.2 dengan melihat nilai composite reliability dan cronbach alpha. Berikut ini hasil dari pengujian:

\section{Tabel 3}

Nilai Construct Reliability and Validity

\begin{tabular}{|l|r|r|r|r|}
\hline & \multicolumn{2}{|l|}{$\begin{array}{l}\text { Cronbach's } \\
\text { Alpha }\end{array}$} & rho A & $\begin{array}{l}\text { Average } \\
\text { Composite } \\
\text { Reliability } \\
\text { Extracted } \\
\text { (AVE) }\end{array}$ \\
\hline AD & 0.729 & 0.736 & 0.846 & 0.647 \\
\hline GA & 0.728 & 0.727 & 0.847 & 0.648 \\
\hline PD & 0.785 & 0.809 & 0.876 & 0.703 \\
\hline PK & 0.760 & 0.762 & 0.862 & 0.676 \\
\hline PR & 0.988 & 0.988 & 0.992 & 0.976 \\
\hline SP & 0.849 & 0.848 & 0.910 & 0.773 \\
\hline TO & 0.823 & 0.867 & 0.896 & 0.744 \\
\hline UA & 0.856 & 0.855 & 0.913 & 0.779 \\
\hline
\end{tabular}

Tabel diatas pada kolom composite reliability nilai seluruh variable diatas 0,7. Sedangkan untuk nilai cronbach alpha nilai seluruh variable diatas 0,6. Maka dapat di simpulkan kuesioner atas seluruh variable sangat reliable dengan nilai reliabilitas yang tinggi.

\subsection{Pengujian Inner Model}

Setelah seluruh indikator dan variabel dinyatakan valid dan reliabel, maka dapat dilakukan analisis inferensial dengan melakukan pengujian inner model. Pengujian ini dilakukan untuk melihat hubungan dari setiap konstruk yang dijadikan model. Berikut ini gambar dari hubungan konstruk beserta nilai korelasi antar konstruk yang dijadikan model penelitian :

Gambar 4

\section{Korelasi Antar Konstruk}

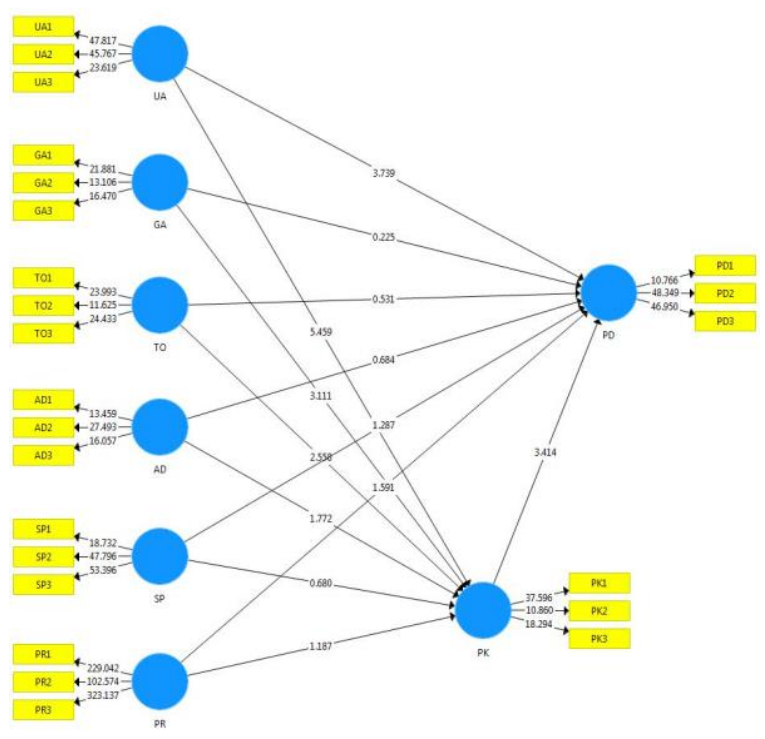

Pengujian inner model dievaluasi menggunakan dua parameter, yakni dengan melihat nilai koefisien determinasi $\left(R^{2}\right)$ dan goodness of fit index (GoF). Berikut ini hasil pengujian dari kedua parameter tersebut:

a) Koefisien Determinasi $\left(R^{2}\right)$

Evaluasi dengan melihat tabel $R$ Square pada output penghitungan software 
SmartPLS Ver. 3.2. Berikut ini hasil output tersebut :

\section{Tabel 4}

Nilai Koefisien Determinasi ( $R$

Square)

\begin{tabular}{|l|r|r|}
\hline & R Square & R Square Adjusted \\
\hline PD & 0.937 & 0.933 \\
\hline PK & 0.928 & 0.924 \\
\hline
\end{tabular}

Pada tabel diatas nilai untuk konstruk Presepsi Konsumen (PK) bernilai 0,928 yang berarti Uncertainty Avoidance (UA), Group Attachment (GA), Time Orientation (TO), Advertising (AD), Sales Promotion (SP) dan Public Relations (PR) mampu menjelaskan varians Presepsi Konsumen (PK) sebesar 0,928 atau $92,8 \%$ sedangkan sisanya dijelaskan oleh variabel lain. Kemudian untuk nilai Purchase Decision (PD) bernilai 0,937 yang berarti Uncertainty Avoidance (UA), Group Attachment (GA), Time Orientation (TO), Advertising (AD), Sales Promotion (SP), Public Relations (PR) dan Presepsi Konsumen (PK) mampu menjelaskan varians Purchase Decision (PD) sebesar 0,937 atau $93,7 \%$ sedangkan sisanya dijelaskan oleh variabel lain.

b) Goodness of Fit Index (GoF)

Untuk memvalidasi model struktural yang diteliti secara keseluruhan dilihat dari skor yang dihasilkan dari penghitungan menggunakan formulasi Tenenhaus sebagai berikut ini :

$\mathrm{GoF}=\sqrt{\overline{A V E}} X \sqrt{\overline{R^{2}}}$

Nilai skor rata-rata AVE dapat dilihat dari Tabel 4.2 sedangkan nilai skor ratarata untuk $R^{2}$ dapat dilihat dari Tabel 4.3.

$$
\begin{aligned}
\text { GoF } & =\sqrt{\overline{A V E}} X \sqrt{\overline{R^{2}}} \\
& =\sqrt{0,74 \times 0,93} \\
& =0,83
\end{aligned}
$$

Dari hasil penghitungan GoF diatas bernilai 0,83 , maka nilai tersebut masuk kedalam kategori indeks sedang atau marginal fit dikarenakan nilai GoF berada pada range indeks $0,80<$ GFI < 0,90. Maka terlihat bahwa model yang dibentuk adalah robust sehingga pengujian hipotesis dapat dilakukan.

\subsection{Pengujian Hipotesis}

Pengujian hipotesis pada penelitian ini dimaksudkan untuk mengukur signifikansi antara variabel eksogen dengan endogen. Hipotesis yang dikembangkan diukur dengan membandingkan nilai t hitung dengan $\mathrm{t}$ tabel pada tingkat signifikansi $10 \%$. Maka didapati nilai $\mathrm{t}$ tabel untuk tingkat signifikansi tersebut adalah 1,66. Dikarenakan pada penelitian ini menggunakan analasis SEM bebrbasis PLS maka metode penghitungan menggunakan teknik bootstraping / resampling.

Kriteria penerimaan ataupun penolakan hipotesis adalah jika thitung $<1,66$ maka $\mathrm{H}$ 
${ }_{0}$ diterima atau $\mathrm{H}_{1}$ ditolak. Berlaku sebaliknya jika $\mathrm{t}$ hitung $>1,66$ maka $\mathrm{H}_{1}$ diterima. Untuk mendapatkan nilai t hitung digunakan software SmartPLS Ver. 3.2 dengan melihat output result of inner weight. Berikut ini hasil output tersebut :

Tabel 5

\section{Result of Inner Weight}

\begin{tabular}{|c|c|c|c|c|c|}
\hline & $\begin{array}{l}\text { Original } \\
\text { Sample (0) }\end{array}$ & $\begin{array}{l}\text { Sample } \\
\text { Mean (M) }\end{array}$ & $\begin{array}{l}\text { Standard } \\
\text { Deviation } \\
\text { (STDEV) }\end{array}$ & $\begin{array}{l}\text { T Statistics } \\
(\mid \mathbf{O} / \text { STDEV } \mid)\end{array}$ & $P$ Values \\
\hline $\mathrm{AD}>\mathrm{PD}$ & -0.083 & -0.088 & 0.121 & 0.684 & 0.494 \\
\hline$A D>P K$ & 0.217 & 0.204 & 0.123 & 1.772 & 0.077 \\
\hline $\mathrm{GA}>\mathrm{PD}$ & -0.097 & -0.273 & 0.431 & 0.225 & 0.822 \\
\hline $\mathrm{GA} \gg \mathrm{PK}$ & 0.678 & 0.729 & 0.218 & 3.111 & 0.002 \\
\hline PK $>$ PD & 0.615 & 0.710 & 0.180 & 3.414 & 0.001 \\
\hline $\mathrm{PR}>\mathrm{PD}$ & -0.720 & -0.543 & 0.453 & 1.591 & 0.112 \\
\hline
\end{tabular}

\subsubsection{Pengujian} Hipotesis 1 (Unceratainty

Avoidance

Berpengaruh Terhadap Presepsi Konsumen)

Hasil pengujian hipotesis pertama menunjukkan bahwa uncertainty avoidance (UA) berpengaruh signifikan terhadap presepsi konsumen (PK). Dari tabel 4.4 nilai t hitung diketahui sebesar 5,459 dengan nilai koefisien 0,514 yang positif. Maka disimpulkan $\mathrm{H}_{1}$ diterima dikarenakan $\mathrm{t}$ hitung $>\mathrm{t}$ tabel $(1,66)$. Hal tersebut dapat diartikan bahwasanya uncertainty avoidance yang identik dengan suatu risiko sangat mempengaruhi Persepsi Konsumen. Secara empiris koefisien yang bernilai positif dapat mengestimasi pengeruh uncertainty avoidance atau risiko searah terhadap presepsi konsumen. Artinya semakin besar peluang adanya resiko semakin besar pula persepsi konsumen atas layanan $e$-commerce.

\subsubsection{Pengujian Hipotesis 2 (Group Attachment Berpengaruh} Terhadap Presepsi Konsumen)

Hasil pengujian hipotesis kedua menunjukkan bahwa group attachment (GA) berpengaruh signifikan terhadap presepsi konsumen (PK). Dari tabel 4.4 nilai t hitung diketahui sebesar 3,1 dengan nilai koefisien 0,678 yang positif. Maka disimpulkan $\mathrm{H}_{1}$ diterima dikarenakan $\mathrm{t}$ hitung $>\mathrm{t}$ tabel $(1,66)$. Hal tersebut dapat diartikan bahwasanya group attachment yang didefinisikan sebagi keterlibatan individu atau komunitas sangat mempengaruhi cara pandang konsumen terhadap e-commerce.

\subsubsection{Pengujian Hipotesis 3 (Time \\ Orientation \\ Berpengaruh}

Terhadap Presepsi Konsumen)

Hasil pengujian hipotesis ketiga menunjukkan bahwa time orientation (TO) berpengaruh signifikan terhadap presepsi konsumen (PK). Dari tabel 4.4 nilai t hitung diketahui sebesar 2,558 dengan nilai koefisien minus 0,364. Maka disimpulkan $\mathrm{H}$ 1 diterima dikarenakan $\mathrm{t}$ hitung $>\mathrm{t}$ tabel $(1,66)$. Hal tersebut dapat diartikan bahwasanya time orientation yang erat akan efisiensi waktu dalam berbelanja merupakan salah satu faktor yang mempengaruhi preepsi konsumen atas cara bebrbelanja dengan media e-commerce. Secara konsep semakin 
sedikit waktu yang dibutuhkan untuk belanja maka dapat mempengaruhi presepsi konsumen akan efisiensi berbelanja. Maka asumsi tersebut searah dengan nilai koefisien yang negatif dan searah dengan konsep.

\subsubsection{Pengujian Hipotesis 4 (Advertising} Berpengaruh Terhadap Presepsi Konsumen)

Hasil pengujian hipotesis keempat menunjukkan bahwa advertising (AD) berpengaruh signifikan terhadap presepsi konsumen (PK). Dari tabel 4.4 nilai t hitung diketahui sebesar 1,772 dengan nilai koefisien positif 0,217. Maka disimpulkan $\mathrm{H}$ 1 diterima dikarenakan $\mathrm{t}$ hitung $>\mathrm{t}$ tabel $(1,66)$. Hal tersebut dapat diartikan bahwasanya advertising yang merupakan sarana membuat image e-commerce dapat mempengaruhi presepsi konsumen atas layananya. Secara empiris nilai koefisien yang positif dapat diartikan semakin banyak volume penyedia jasa e-commerce membuat advertising maka presepsi konsumen akan tumbuh atas layanan e-commerce.

\subsubsection{Pengujian Hipotesis 5 (Sales Promotion Tidak Berpengaruh Terhadap Presepsi Konsumen)}

Hasil pengujian hipotesis kelima menunjukkan bahwa sales promotion (SP) tidak berpengaruh signifikan terhadap presepsi konsumen (PK). Dari tabel 4.4 nilai t hitung diketahui sebesar 0,680 dengan nilai koefisien positif 0,066. Maka disimpulkan $\mathrm{H}$
0 diterima dikarenakan $\mathrm{t}$ hitung $<\mathrm{t}$ tabel $(1,66)$. Hal tersebut dapat diartikan bahwasanya sales promotion yang dilakukan oleh penyedia jasa e-commerce tidak mempengaruhi presepsi konsumen secara signifikan. Nilai koefisien yang positif dapat dijadikan acuan agar penyedia layanan semakin kreatif dan gencar membuat sales promotion. Secara empiris semakin banyak program sales promotion maka semakin menarik perhatian konsumen, hal tersebut dapat dijadikan trigger bagi penyedia layanan e-commerce agar presepsi konsumen meningkat.

\subsubsection{Pengujian Hipotesis 6 (Public Relations Tidak Berpengaruh Terhadap Presepsi Konsumen)}

Hasil pengujian hipotesis keenam menunjukkan bahwa public relations (PR) tidak berpengaruh signifikan terhadap presepsi konsumen (PK). Dari tabel 4.4 nilai t hitung diketahui sebesar 1,187 dengan nilai koefisien negatif 0,174. Maka disimpulkan $\mathrm{H}$ 0 diterima dikarenakan $\mathrm{t}$ hitung $<\mathrm{t}$ tabel $(1,66)$. Hal tersebut dapat diartikan bahwasanya public relations yang dilakukan oleh penyedia jasa e-commerce tidak mempengaruhi presepsi konsumen secara signifikan.

\subsubsection{Pengujian Hipotesis 7 (Presepsi} Konsumen Berpengaruh Terhadap Purchase Decision) 
Hasil pengujian hipotesis ketujuh menunjukkan bahwa presepi konsumen (PK) berpengaruh signifikan terhadap purchase decision (PD). Dari tabel 4.4 nilai t hitung diketahui sebesar 3,414 dengan nilai koefisien positif 0,615. Maka disimpulkan $\mathrm{H}$ 1 diterima dikarenakan $\mathrm{t}$ hitung $>\mathrm{t}$ tabel $(1,66)$. Hal tersebut dapat diartikan bahwasanya apa yang dipresepsikan oleh konsumen merupakan salah satu parameter konsumen membuat keputusan untuk berbelanja dengan platform e-commerce. Secara empiris nilai koefisien yang positif maka perubahan estimasi nilai presepsi konsumen berpengaruh searah terhadap purchase decision. Dapat diartikan semakin besar nilai yang dipresepsikan oleh konsumen smakin besar pula potensi konsumen untuk berbelanja secara on-line.

\subsubsection{Pengujian Hipotesis 8 (Uncertainty} Avoidance Berpengaruh Terhadap

\section{Purchase Decision)}

Hasil pengujian hipotesis kedelapan menunjukkan bahwa uncertainty avoidance (UA) berpengaruh signifikan terhadap purchase decision (PD). Dari tabel 4.4 nilai $\mathrm{t}$ hitung diketahui sebesar 3,739 dengan nilai koefisien positif 0,864 . Maka disimpulkan $\mathrm{H}$ 1 diterima dikarenakan $\mathrm{t}$ hitung $>\mathrm{t}$ tabel $(1,66)$. Hal tersebut dapat diartikan bahwasanya suatu ketidak pastian yang dirasakan oleh konsumen merupakan salah satu faktor penentu bagi konsumen untuk membuat keputusan berbelanja dengan platform e-commerce. Secara empiris koefisien yang bernilai positif maka perubahan estimasi nilai uncertainty avoidance berpengaruh searah terhadap purchase decision. Dapat diartikan semakin besar suatu ketidak pastian yang dirasakan oleh konsumen maka akan menjadi parameter yang dominan untuk membuat keputusan pembelian (purchase decision).

\subsubsection{Pengujian Hipotesis 9 (Group Attachment Tidak Berpengaruh Terhadap Purchase Decision) \\ Hasil pengujian hipotesis kesembilan} menunjukkan bahwa group attachment (GA) tidak berpengaruh signifikan terhadap purchase decision (PD). Dari tabel 4.4 nilai $\mathrm{t}$ hitung diketahui sebesar 0,225 dengan nilai koefisien negatif 0,097. Maka disimpulkan $\mathrm{H}$ 0 diterima dikarenakan $\mathrm{t}$ hitung $<\mathrm{t}$ tabel $(1,66)$. Hal tersebut dapat diartikan bahwasanya group attachment dari anggota masyarakat tidak bisa dijadikan parameter penentu untuk membuat keputusan pembelian (purchase decision) dengan platform e-commerce.

\subsubsection{Pengujian Hipotesis 10 (Time Orientation Tidak Berpengaruh Terhadap Purchase Decision)}

Hasil pengujian hipotesis kesepuluh menunjukkan bahwa time orientation (TO) tidak berpengaruh signifikan terhadap purchase decision (PD). Dari tabel 4.4 nilai $\mathrm{t}$ 
hitung diketahui sebesar 0,531 dengan nilai koefisien positif 0,091. Maka disimpulkan $\mathrm{H}$ 0 diterima dikarenakan $\mathrm{t}$ hitung $<\mathrm{t}$ tabel $(1,66)$. Hal tersebut dapat diartikan bahwasanya time orientation yang di presepsikan efisien oleh konsumen tidak lantas mempengaruhi purchase decision dari konsumen. Dapat terlihat konsumen masih cendrung membeli secara konvensional karena terdapat hal-hal lain yang menjadi pertimbangan selain dari efisiensi yang di presepsikan.

\subsubsection{Pengujian Hipotesis 11 (Advertising Tidak Berpengaruh Terhadap Purchase Decision) \\ Hasil pengujian hipotesis kesebelas} menunjukkan bahwa advertising (AD) tidak berpengaruh signifikan terhadap purchase decision (PD). Dari tabel 4.4 nilai t hitung diketahui sebesar 0,684 dengan nilai koefisien negatif 0,083 . Maka disimpulkan $\mathrm{H}$ ${ }_{0}$ diterima dikarenakan $\mathrm{t}$ hitung $<\mathrm{t}$ tabel $(1,66)$. Hal tersebut dapat diartikan bahwasanya advertising bukan sebagai faktor pendorong konsumen atau masyarakat agar melakukan pebelian secara on-line. Melainkan sebagai media untuk memperkenalkan layanan e-commerce serta untuk menumbuhkan image.

\subsubsection{Pengujian Hipotesis 12 (Sales Promotion Tidak Berpengaruh Terhadap Purchase Decision)}

Hasil pengujian hipotesis keduabelas menunjukkan bahwa sales promotion (SP) tidak berpengaruh signifikan terhadap purchase decision (PD). Dari tabel 4.4 nilai $\mathrm{t}$ hitung diketahui sebesar 1,287 dengan nilai koefisien positif 0,224 . Maka disimpulkan $\mathrm{H}$ 0 diterima dikarenakan $\mathrm{t}$ hitung $<\mathrm{t}$ tabel $(1,66)$. Hal tersebut dapat diartikan bahwasanya program sales promotion tidak mendorong konsumen atau masyarakat agar melakukan pebelian secara on-line. Nilai koefisien yang positif dapat menjadi trigger bagi penyedia layanan e-commerce untuk membuat program promosi yang menarik bagi konsumen agar dapat menjadi salah satu faktor dalam melakukan pembelian.

\subsubsection{Pengujian Hipotesis 13 (Public Relations Tidak Berpengaruh Terhadap Purchase Decision)}

Hasil pengujian hipotesis ketigabelas menunjukkan bahwa public relations (PR) tidak berpengaruh signifikan terhadap purchase decision (PD). Dari tabel 4.4 nilai $\mathrm{t}$ hitung diketahui sebesar 1,591 dengan nilai koefisien negatif 0,720 . Maka disimpulkan $\mathrm{H}$ 0 diterima dikarenakan $\mathrm{t}$ hitung $<\mathrm{t}$ tabel $(1,66)$. Hal tersebut dapat diartikan bahwasanya kegiatan/sarana public relations tidak mendorong konsumen atau masyarakat agar melakukan pebelian secara on-line.

\subsection{Analisa Direct, Indirect dan Total Effects}


Setelah pengujian hipotesis dilakukan maka selanjutnya dilakukan analisa pengaruh antar konstruk dari model penelitian yang dikembangkan baik secara langsung, tidak langsung ataupun pengaruh totalnya. Berikut ini merupakan hasil dari pengaruh langsung dari konstruk yang telah diolah berdasarkan referensi table result of inner weight:

\section{Tabel 6}

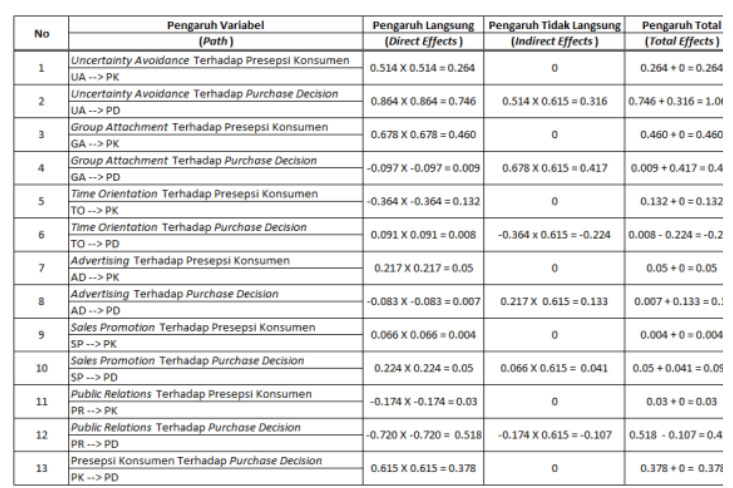

Direct, Indirect \& Total Effects

Berdasarkan hasil pengolahan direct effects pada tabel 4.5 menunjukan bahwa variabel yang memiliki pengaruh langsung terbesar kepada konstruk presepsi konsumen adalah variabel group attachment dengan koefisien sebesar 0,460. Sedangkan untuk pengaruh langsung terhadap konstruk purchase decisions adalah variabel uncertainty avoidance dengan koefisien sebesar 0,746.

Selanjutnya akan diukur pengaruh tidak langsung antar konstruk, seperti pengukuran yang tergambar pada tabel 4.5 variabel yang memiliki pengaruh tidak langsung terbesar terhadap konstruk purchase decisions adalah variabel group attachment dengan koefisien sebesar 0,417.
Dikarenakan adanya hubungan tidak langsung dan hubungan langsung maka perlu dilakukan pengukuran total variabel. Berdasarkan hasil pengukuran sesuai tabel 4.5 diketahui variabel yang memiliki pengaruh total terbesar terhadap konstruk presepsi konsumen adalah variabel group attachment dengan nilai koefisien sebesar 0,460 . Sedangkan pengaruh total terbesar untuk konstruk purchase decisions adalah variabel uncertainty avoidance dengan nilai koefisien sebesar 1,062.

\section{KESIMPULAN}

Berdasarkan hasil analisis bab sebelumnya seluruh indikator yang dijadikan parameter penelitian memiliki nilai validitas tinggi diatas cut off value sebesar 0,7 atau $70 \%$. Sedangkan untuk pengujian insturumen penelitian seluruh jawaban setiap indikatornya sangat reliabel, hal ini ditunjukan oleh nilai composite reliability diatas 0,7 atau $70 \%$ dan nilai cronbach alpha diatas 0,6 atau $60 \%$. Selanjutnya untuk model penelitian dinyatakan robust yang diukur oleh dua parameter. Parameter pertama nilai koefisien $r$ square sebesar $92,8 \%$ dan $93,7 \%$ untuk konstruk presepsi konsumen dan purchase decision. Dapat diartikan seluruh variabel independen dapat menjelaskan problem variabel dependen diatas $90 \%$. Parameter kedua menunjukan model yang diteliti dalam kategori marginal fit dikarenakan nilai penghitungan goodnes of fit berada pada range indeks $0,80-0,90$. 
Kemudian dari model penelitian yang dikembangkan dalam penelitian ini hubungan konstruk hubungan tidak langsung antara variable group attachment dengan purchase decision adalah yang paling kuat dengan koefisien 0,417. untuk konstruk hubungan langsung terhadap variable presepsi konsumen yang paling kuat adalah variable group attachment dengan koefisien sebesar 0,460 . Sedangkan terhadap variable purchase decision pengaruh variable uncertainty avoidance memiliki pengaruh yang paling kuat dengan koefisien sebesar 0,746.

Dari rumusan masalah yang dijadikan acuan pada penelitian ini dapat dijawab melalui hipotesis model struktural yang telah ditelaah. Bahwasanya dapat disimpulkan seluruh atribut dimensi budaya berpengaruh terhadap presepsi konsumen. Sedangkan pada dimensi komunikasi hanya atribut advertising yang berpengaruh terhadap presepsi konsumen. Sedangkan atribut dimensi budaya yang berpengaruh terhadap purchase decision hanya uncertainty avoidance. Atribut dimensi komunikasi tidak ada yang berpengaruh terhadap purchase decision.

\section{DAFTAR PUSTAKA}

Aristo Surya, 2009 "Analisis Persepsi Konsumen Pada Aplikasi bauran pemasaran SertaHubunganya Terhadap Loyalitas Konsumen (Studi Kasus Pada Hypermart Cabang kelapa Gading)", Journal of Business Strategy and Execution 2 Unika Atmajaya.
Basu Swasta \& Irawan, 2008 Manajemen Pemasaran Modern, Liberty, Yogyakarta

Catherine L. Mann \& Sue E. Eckert, 2000 Global Electronic Commerce: A Policy Primer, Peterson Institute for International Economics.

David I. Loudon \& Albert J. della Bitta, 1993 Consumer Behavior: Concept and Applications. Ed, mc Graw-Hill, Incorporation.

Devia Arda, "Perbandingan Konsep Nilai Budaya Dengan Menggunakan Kerangka Kerja Hofstede", Master Thesis Universitas Diponegoro.

Efraim Turban \& David King, 2012 Electronic Commerce, Global Edition 7/E, Pearson.

Fandy Tjiptono, 2007 Pemasaran Jasa, Edisi pertama cetakan ketiga Banyumedia Publishing, Malang. , Strategi Pemasaran, Edisi 3 Andi Offset, Yogyakarta.

Henry Assael, Consumer Behavior and Marketing Action, 6 th Edition, Western College Publishing.

Jalaluddin Rakhmat, 2007 Psikologi komunikasi, PT. Remaja Rosdakarya.

Janner Simamarta, 2005, Pengenalan Teknologi Komputer dan Informasi, Andi Offset, Yogyakarta.

John Kennedy \& Rd Soemanagara, 2006 Marketing Communication - Taktik dan Strategi, PT. Buana Ilmu Populer.

Kanuk \& Shiffman, 2004 Consumer Behavior, Prentice Hall, Jakarta. 
Kenneth C. Laudon \& Carol Guercio Traver, 2010 E-commerce (business, technology, society), Pearson.

Kruti Shah \& Alan D'souza, 2009 Advertising and Promotion : an IMC Perspective, McGraw-Hill.

Marina Tangko et al, 2013 "Analisis Bauran Pemasaran Yang Mempengaruhi Keputusan Pembelian Konsumen Di Just Coffee Speciality Surabaya", Jurnal Hospitality dan Management Jasa Universitas Kristen Petra, Volume 4.

Milton Rokeach, 1973 The Nature of Human Values, Free Press.

Nguyen Phuong Mai, 2015 "Hofstede's Five Value Dimensions Of Culture", CCA Course Paper University of Amsterdam.

Praba Sulistyawati, 2013 "Analisis Pengaruh Citra Merek Dan Kualitas citra Produk Terhadap Keputusan Pembelian Laptop Merek Acer Di Kota Semarang", Jurnal Fakultas Ekonomi Manajemen Universitas Diponegoro.

Purimahua, 2005 "Faktor-Faktor yang Berpengaruh terhadap Perilaku Mahasiswa dalam Memilih Jurusan Ekonomi Pembangunan pada Fakultas Ekonomi Universitas Kristen Maluku di Ambon", Jurnal Keuangan dan Perbankan, Volume 9.

T. Aliyuddinsyah, 2008 Sales dan Marketing, Pusat dan Bahan Ajar eLearning Universitas Mercubuana.

Tatik Suryani, 2008 Perilaku Konsumen: Implikasi pada Strategi Pemasaran, Graha Ilmu.

Rahmat Ramadhan, 2013 "Persepsi Mahasiswa Terhadap Penggunaan Poduk Smartphone Blackberry (Studi Kasus Pada Mahasiswa Politeknik Negeri Jurusan Teknik Kimia)", Karya Ilmiah Jurusan Administrasi Bisnis Politeknik Sriwijaya, Tidak Dipublikasi.
Rd Soemanagara, 2012 Strategic Marketing Communication: Konsep Strategis dan Terapan, Alfabeta.

Rhendira Dinawan, 2010 "Analisis FaktorFaktor Yang Mempengaruhi Keputusan Pembelian (Studi Kasus Pada Konsumen Yamaha Mio PT. Harpindo Jaya Semarang)", Tesis Magister Manajemen Universitas Diponegoro.

Sugiyono, 2006 Metode Penelitian Bisnis cetakan kesembilan, Alfabeta, Bandung.

Suharsimi Arikunto, 2006 Prosedur Penelitian Suatu Pendekatan Praktik, Edisi Revisi VI, PT. Rineka Cipta, Jakarta.

Sunyoto, 2013 Proses Pengambilan keputusan Konsumen, CAPS.

Venny Rizki Amelia Aziz, 2015 "Pengaruh Persepsi Risiko Dan Gaya Hidup Terhadap Keputusan Pembelian Pakaian Secara Online Melalui Blackberry Messengger (BBM)", eJournal Psikologi Universitas Mulawarman.

Vera Pujiani \& Eri Besra, 2009 "Pelatihan Penggunaan Teknologi Internet Dikalangan Pengusaha Bordir Di Kota Bukittinggi”, Jurnal Warta Pengabdian Andalas, Volume 25.

Yusnindar et al, 2014 "Pengaruh Kepercayaan dan Persepsi Resiko Terhadap Minat Beli Dan Keputusan Pembelian Produk Fashion Secara Online Di Kota Pekanbaru", Jurnal Sosial Ekonomi Pembangunan Universitas Riau, Volume 12. 